\title{
Familial atrial standstill caused by amyloidosis
}

\author{
SHIGERU MAEDA, TOSHIHIDE TANAKA, TAKAKAZU HAYASHI \\ From the Department of Medicine, Sakakibara Heart Institute, Yoyogi, Shibuya-ku, Tokyo, Japan
}

SUMMARY Three of nine siblings were affected by atrial standstill. Clinical, electrophysiological, and histological findings in two of these cases were studied. Electrophysiological studies showed persistent atrial standstill in one and partial atrial standstill in the other. Biopsy specimens of the right atria showed amyloid deposits, but specimens of the right ventricles and skin did not. Neither patient had peripheral neuropathy, gastrointestinal disorder, or renal dysfunction. Familial atrial standstill is usually associated with peripheral neuropathy.

In the two cases studied amyloid deposition mainly affected the atrium, rather than the ventricles or other organs, and caused atrial standstill.

Amyloidosis is a cause of atrial standstill. ${ }^{1-3}$ The most common clinical feature of cardiac amyloidosis is rapidly progressive heart failure ${ }^{45}$; familial amyloidosis is usually also associated with peripheral neuropathy. ${ }^{6}$ We report on three cases of familial atrial standstill caused by amyloidosis in which there were no cardiac symptoms or peripheral neuropathy.

\section{Case reports}

CASE 1

A 36 year old man had a sudden onset of left hemiparesis on 29 October 1984. Cerebral infarction was diagnosed and bradycardia and cardiomegaly were found. On 29 November 1984 he was admitted to our hospital for further evaluation. On admission his pulse was regular at 48 beats $/ \mathrm{min}$ and blood pressure was $140 / 80 \mathrm{~mm} \mathrm{Hg}$. A grade $2 / 6$ ejection systolic murmur was heard along the left sternal border. The second sound was split widely and the width of splitting increased during the inspiratory phase. Neurological examination showed left hemiparesis and a mild speech disturbance.

An electrocardiogram showed a ventricular rate of 39 beats/min with complete right bundle branch block and a QRS width of $0 \cdot 12 \mathrm{~s}$. No $P$ waves were found in any of the leads. Intravenous atropine sulphate $(1.0 \mathrm{mg})$ and exercise increased the ventricular rate to 64 and 118 beats $/ \mathrm{min}$, respectively, but $P$ waves remained absent.

Requests for reprints to Dr Shigeru Maeda, Department of Cardiology, Tokyo Metropolitan Geriatric Hospital, 35-2, Sakae-cho, Itabashi-ku, Tokyo 173, Japan.

Accepted for publication 5 November 1987
Chest $x$ rays showed cardiomegaly with a cardiothoracic ratio of $0 \cdot 6$. The echocardiogram showed dilatation of the right atrium with no A waves on the anterior mitral leaflet, but the wall thickness and contraction of the left ventricle were normal.

Cardiac catheterisation showed no a waves on the right atrial pressure curve. An intracardiac electrogram from the right atrium showed no A waves, fibrillary waves, or any other electrical activity. No extrasystoles could be induced by right atrial stimulation even at an output of $10 \mathrm{~V}$. On the other hand, intrinsic ventricular contractions had a $R$ wave amplitude of $14 \mathrm{mV}$, and artificial stimulation produced right ventricular activation at $0.3 \mathrm{~V}$.

Biopsy samples from the right atrial wall showed amyloid deposits and considerable muscle loss with replacement fibrosis. But samples from the right ventricle, skin, and rectum showed no evidence of amyloid deposition.

The patient had a permanent pacemaker implanted and has been treated with oral anticoagulants to prevent systemic embolism. He continues to do well with regular visits to our outpatient clinic.

\section{CASE 2}

The 34 year old brother of case 1 was found to have bradycardia and cardiomegaly at the age of 27 . On 30 November 1983 he was admitted to hospital with lower abdominal pain of sudden onset which was accompanied by an increase in the serum concentrations of glutamic oxaloacetic transaminase, glutamic pyruvic transaminase, and lactate dehydrogenase. Lower abdominal pain disappeared in a few days and enzyme concentrations returned to normal within two weeks, but the cause of lower abdominal pain was 

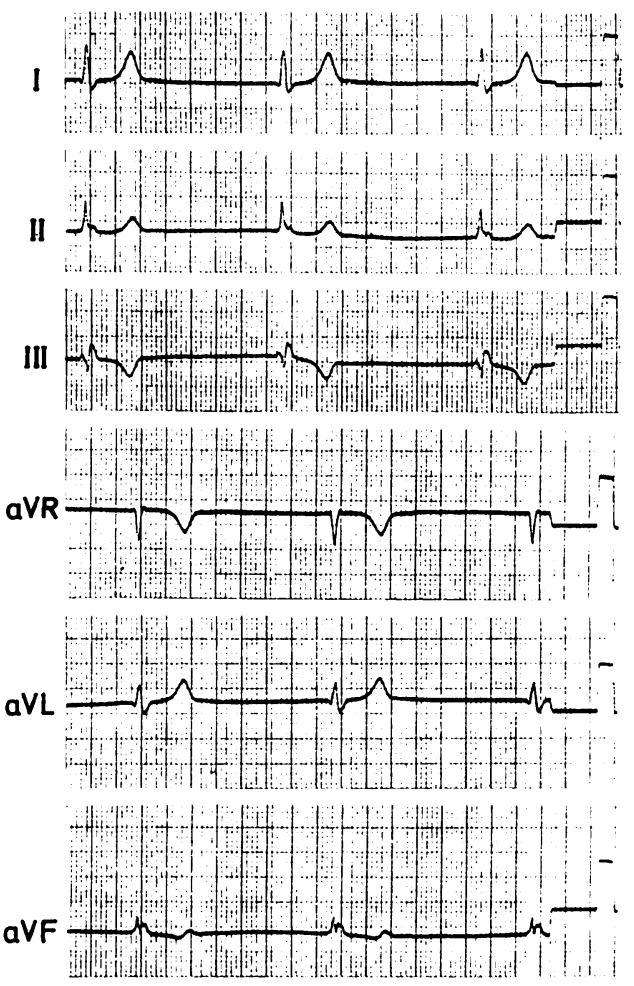
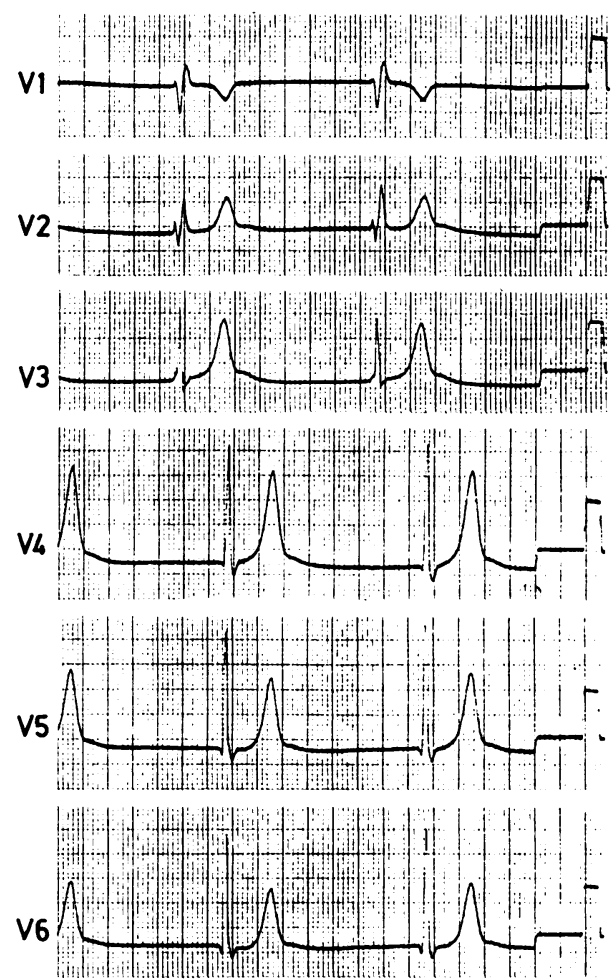

Figure Electrocardiogram of case 1 showing absence of $P$ waves and slow regular atrioventricular junctional rhythms in all leads.

never determined. He was admitted to our hospital for further evaluation on 31 March 1984.

On admission his pulse was regular at 35 beats $/ \mathrm{min}$ and blood pressure was $140 / 80 \mathrm{~mm} \mathrm{Hg}$. There was no peripheral oedema and the liver and spleen were not palpable. A grade $2 / 6$ ejection systolic murmur was heard along the left sternal border. The second sound was widely split and splitting increased during the inspiratory phase. The neurological examination was normal.

An electrocardiogram showed a ventricular rate of 44 beats $/ \mathrm{min}$ with a $Q R S$ width of $0.08 \mathrm{~s}$. No $P$ waves were found in any leads. By contrast, an electrocardiogram obtained seven years earlier showed occasional low voltage $P$ waves $(\cong 0.1 \mathrm{mV}$ ) which were conducted to the ventricles, and one recorded a year earlier showed low voltage atrial flutter waves ( $\cong 0.05 \mathrm{mV}$ ) with a cycle length of $180 \mathrm{~ms}$ on leads II, III, and aVF accompanied by a ventricular rate of 40 beats $/ \mathrm{min}$. Intravenous atropine sulphate $(1.0 \mathrm{mg})$ and exercise at our clinic increased the ventricular rate to 72 and 120 beats/min respectively, but no $P$ waves appeared. Chest $x$ rays showed cardiomegaly with a cardiothoracic ratio of $0 \cdot 64$.

An echocardiogram showed dilatation of the right atrium, no $A$ waves on the anterior mitral leaflet, and normal thickness and contraction of the ventricular wall (as in case 1).

Cardiac catheterisation showed no a waves on the right atrial pressure curve. A right atrial intracardiac electrogram, however, showed very low voltage flutter waves with a cycle length of $175 \mathrm{~ms}$. A simultaneous surface electrocardiogram did not show flutter waves in any leads. Atrial capture could not be achieved with stimuli up to $10 \mathrm{~V}$. On the other hand, the right ventricle showed normal response to stimulation at $0.5 \mathrm{~V}$ and $\mathrm{R}$ wave amplitude was normal.

Biopsy specimens of the right atrium, right ventricle, and skin were obtained for pathological examination. Only the right atrium contained amyloid deposits (as in case 1). Specimens from the right ventricle and skin were normal.

This patient also had a permanent pacemaker implanted because of considerable bradycardia. $\mathrm{He}$ remains well. 
CASE 3

The 47 year old brother of the two previous patients was found to have bradycardia and cardiomegaly (cardiothoracic ratio 0.66 ) at another hospital when he was 37 . An electrophysiological study was performed at the time, and a right atrial intracardiac electrogram showed no $A$ waves. The right ventricle responded to stimulation at $0.6 \mathrm{~V}$ and $\mathrm{R}$ wave amplitude was $5.2 \mathrm{mV}$. Atrial standstill was diagnosed. A biopsy specimen of the right ventricle showed no abnormalities.

This patient also had a permanent pacemaker implanted for considerable bradycardia at the age of 42. When he was 46 pretibial oedema developed and chest $x$ rays showed an increase of cardiothoracic ratio to $0 \cdot 75$. After a one month stay in hospital the pretibial oedema disappeared and his cardiothoracic ratio fell to $0 \cdot 69$. He is being followed at another outpatient clinic and his condition has not deteriorated.

Six other siblings of the above patients (five women and one man) have not been examined.

\section{Discussion}

Although familial atrial standstill has been reported, ${ }^{7-9}$ its aetiology was confirmed only by Allensworth et al and Harrison and Derric. Allensworth et al studied three siblings with atrial standstill and showed right atrial amyloid deposits in one of them. ${ }^{1}$ Harrison and Derric reported two siblings with almost identical clinical and electrocardiographic features, and showed right atrial amyloid deposition in one. ${ }^{2}$ There is also a report by Williams et al on familial atrial standstill that reports considerable muscle loss in only the right atrial wall with replacement fibrosis and no evidence of amyloid deposition. $^{10}$

On the other hand, many cases of familial amyloidosis have been reported. In most of them the characteristic clinical findings are associated with peripheral neuropathy, ${ }^{611}$ but cardiac failure is also found, ${ }^{12}$ though less often. There are also many reports of cardiac amyloidosis. ${ }^{45}$ The most common clinical feature is congestive heart failure, which is often refractory to treatment. Although electrocardiograms in cases of cardiac amyloidosis and familial amyloidosis frequently show sinus node dysfunction, abnormalities of atrioventricular conduction and other arrhythmias, ${ }^{13}{ }^{14}$ atrial standstill is rarely seen.

Familial atrial standstill caused by amyloidosis was diagnosed in our three cases. None of them had peripheral neuropathy, rapidly progressive cardiac failure, gastrointestinal disorder, or renal dysfunc- tion. The clinical, electrophysiological, and path- $\frac{\mathbb{D}}{7}$ ological findings of our cases differ from those of $c$ familial amyloidosis or cardiac amyloidosis reported $\overrightarrow{\vec{F}}$ earlier. Although the cases of Allensworth and Harr- $-\frac{\rho}{9}$ ison seem to resemble our cases clinically, electrophysiologically, and pathologically, they did not have $\frac{\overline{\bar{O}}}{\bar{D}}$. the same electrophysiological and pathological find- $\frac{\bar{\omega}}{\bar{\phi}}$ ings in the ventricle. Frederiksen et al stated that in $\cong$ familial amyloidosis, "Case reports show a high" degree of uniformity within each family, whereas the $\vec{\circ}$ symptoms may vary considerably from one family to another." 12 We agree, and we believe that the most $\vec{\omega}$ important finding in our series was that amyloid deposition mainly affected the atrium rather than the ventricle or other organs and caused atrial standstill. 0

\section{References}

1 Allensworth DC, Rice GJ, Lowe GW. Persistent atrial $\stackrel{\circ}{\text { ? }}$ standstill in a family with myocardial disease. $\mathrm{Am} \mathrm{J}_{\vec{\nabla}}$ Med 1969;47:775-84.

2 Harrison WH, Derric JR. Atrial standstill: a review, and presentation of two new cases of familial and unusual $\vec{\oplus}$ nature with reference to epicardial pacing in one. $\infty$ Angiology 1969;20:610-7.

3 Combs DT, Bellaci HF, Shively HH, Gregoratos G. Persistent atrial standstill. Am J Med 1974;56:231-6.

4 Kyle RA, Baynd ED. Amyloidosis: review of 236 cases. Medicine (Baltimore) 1975;54:271-99.

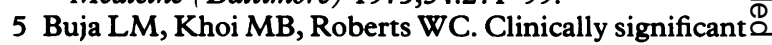
cardiac amyloidosis. Am J Cardiol 1970;26:394-405. $\overrightarrow{\overrightarrow{0}}$

6 Andrade C. A peculiar form of peripheral neuropathy. $\frac{3}{3}$ Familial atypical generalized amyloidosis with special involvement of the peripheral nerves. Brain O 1952;75:408-27.

7 Arita $M$, Yamaguchi $M$, Nagasue S. A family of myocardiopathy with marked bradycardia. Shinzo $\stackrel{\varrho}{\rightleftharpoons}$ 1970;2:59-68 [in Japanese].

8 Kurokawa A, Kurita A, Kasai G, Kimura E. Persistent atrial standstill: report of three cases. J Electrocardiol $\hat{\circ}^{\circ}$ 1975;8:357-62.

9 Bayne EJ, Chandramouli B, Cancilla PA, Lauer RM. Familial prolonged atrial standstill presenting in infancy. J Pediatr 1980;97:953-6.

10 Williams DO, Smith BS, Nagle RE, Jones EL. Familial atrial cardiomyopathy with heart block. $Q J M e d / N$ 1972;41:491-502.

11 Benson MD, Cohen AS. Generalized amyloid in a family of Swedish origin. Ann Intern Med 1977;86:419-24.

12 Frederiksen T, Gotzsche H, Harboe N. Familiako primary amyloidosis with severe amyloid heart disease. Am J Med 1962;33:328-48.

13 Ridolf RL, Bulkley BH, Hutchins GM. The conduction system in cardiac amyloidosis. $\mathrm{Am} \mathrm{J}$ Med 1977; 62:677-86.

14 Thomas NJ. Pathology of the cardiac conduction sys- $\frac{\stackrel{?}{\circ}}{\circ}$ tem in amyloidosis. Ann Intern Med 1966;65:28-36. 